\title{
Article
}

\section{Can Producers' Price War End Up in an Optimal Allocation?}

\author{
Marta Kornafel (1D \\ Department of Mathematics, Cracow University of Economics, ul. Rakowicka 27, 31-510 Kraków, Poland;
marta.kornafel@uek.krakow.pl
}

check for

updates

Citation: Kornafel, M. Can Producers'

Price War End Up in an Optimal

Allocation? Mathematics 2022, 10, 265

https://doi.org/10.3390/

math10020265

Academic Editor: David Barilla

Received: 10 December 2021

Accepted: 13 January 2022

Published: 16 January 2022

Publisher's Note: MDPI stays neutral with regard to jurisdictional claims in published maps and institutional affiliations.

Copyright: (C) 2022 by the authors. Licensee MDPI, Basel, Switzerland. This article is an open access article distributed under the terms and conditions of the Creative Commons Attribution (CC BY) license (https:// creativecommons.org/licenses/by/ $4.0 /)$.

\begin{abstract}
The paper presents a theoretical framework for the phenomenon of the price war in the context of general equilibrium, with special attention to the production system. The natural question that arises is whether Nash-optimal production plans being the reactions to the changing prices can finally approximate a Nash-optimal production plan at the end of this war. To provide an answer, the production system is described as a parametric-multicriteria game. Referring to some results on the lower semicontinuty of the parametric weak-multicriteria Nash equilibria, we provide a positive answer for the stated problem.
\end{abstract}

Keywords: general equilibrium; lower semicontinuity of weak Nash equilibria; price war

JEL Classification: C70; D21; D50

\section{Introduction}

The model of general equilibrium by G. Debreu [1] describes the structure of the economy, taking into account the interactions between two main groups of the market agents: consumers and producers. Given the prices of a finite number of goods, the consumers aim to maximize their preferences, choosing suitable consumption plans in their budget sets while the producers head to profit maximization over their production sets. Debreu showed that under suitable assumptions, it is possible to assure the equilibrium state understood as Pareto equilibrium.

This model was an inspiration for further studies. The behaviour of agents was modelled in a topological framework or via the game theory approach. Among other research works, A. Malawski developed this model to describe the Schumpeterian changes of economy (see [2,3]). To remind briefly, J.A. Schumpeter [4] determined two forms of economic life: circular flow and economic development. The first form corresponds to a state when all the processes and agents follow the known economic rules, even if some new goods appear in the market. The second form, economic development, can be obtained via creative destruction, defined as the natural process of introducing innovations and eliminating the existing goods, production technologies, markets, etc. Schumpeter [4] describes: "The fundamental impulse that acts and keeps the capitalistic engine in motion comes from the new consumers' goods, the new method of production, the new forms of industrial organization that capitalist enterprise creates. (...) The opening up of new markets, foreign or domestic, and the organizational development (...) illustrate the same process of industrial mutation-if I may use that biological term - that revolutionizes the economic structure from within, incessantly destroying the old one, incessantly creating a new one." How the creative destruction changes the circular flow was not explained by Schumpeter. Such attempts were undertaken in the research program on Schumpeterian evolution of economy, initialized by A. Malawski [5]. In the axiomatic-topological framework, the cumulative and innovative extensions of a production system were defined and their properties proved [2], including the economic mechanisms describing the evolution from an arbitrary economic system to its cumulative extension (price-preserving mechanism) and evolution to its innovative extension (qualitative mechanism) [3]. Moreover, it was proved [6] that acting optimally 
at each stage of the evolution in both those processes, the producers are able to reach an optimal state in the final system.

In the business literature, the price wars are defined in a descriptive way and it seems there is no unified approach. Assael [7] stated that a price war is an effect of competition between firms, struggling to undercut each other. Urban and Star [8] noted that a price war happens if one of the companies attempts to grab market share by lowering its price and competitors must match this. Busse [9] claimed that a price war is a period in which the firms set prices that are significantly below the prices typically charged in the industry. Basically, the research found that a long-lasting price war may cause severe consequences for the economy as the companies suffer losses and may loose the ability to innovate, and the consumers despite initial benefits from lower prices may come to unrealistic reference prices and suffer from a lower quality of products (see citations above). Heil and Helsen ([10], Table 1, pp. 84-85) provided the list of different examples of branches where a price war occurred. To mention only a few from the US and Europe: battles between the producers of electronic hardware and software, contact lenses or car tires. Some other examples from Africa and Australia may be found in [11-13]. All the cited research refers to some statistical data.

The character of interaction between the producers competing in the market naturally suggests the use of a game-theoretic approach to describe those interactions formally. Such attempts were made, for instance, in [14-16]. However, the proposed models are modifications of the classical model of prisoner's dilemma.

In this paper, we present the production system of a general equilibrium model described in the language of game theory. We allow an arbitrary number of producers whose production abilities are characterized by their production sets. They may decide to lower the price, changing in this way their set of possible production plans that maximize the profit. This is an impulse that causes the price war in the market. This impulse could be interpreted as a creative destruction of the economic system that changes the market and leads to some evolutionary change of the system. In this sense, it is also a contribution in the description of the Schumpeterian theory.

The main concern of this paper is to answer the following question: whether the producers, facing the changing prices and adjusting to them their choices concerning the best production plans available, finally end up in an optimal production plan for the final prices. "Best" choices are understood as suitable Nash equililbria. In order to provide the answer for the question posed, first, we recall the concept of a parametric-multicriteria game and the result on lower semicontinuity of the parametric multicriteria-weak Nash equilibria, following [17]. Formulation of this theorem requires Kuratowski convergence of suitable sequences of sets. Next, we briefly describe the production system of a general equilibrium model. In the fourth section, the description of the production sector is adjusted to the framework of a parametric-multicriteria game. Finally, the theorem assuring the lower semicontinuity of the considered Nash equilibria is interpreted in the context of the price war.

It is worth emphasizing that we do not study the existence of an optimal solution at each stage of the evolution, assuming that they exist. The price war is formally modelled as a convergent sequence of price vectors. As it is quite natural to expect that the sequence of prices is decreasing (in the lexicographic order), it may be not that obvious that it is a convergent sequence. However, it seems reasonable to assume some lower bound for the sequence of prices, under which the further lowering is not justified economically. Then, referring to the property that a bounded monotone sequence is convergent in $\mathbb{R}^{n}$, the convergence is not unrealistic. For nonmonotone sequences, we need to assume their convergence. 


\section{Multicriteria Game and Weak Nash Equilibria}

In this part, the general description of multicriteria game will be provided and the theorems used later in the analysis will be formulated. This part follows the description in [17].

The $N$ player multicriteria game can be described in the following way. Let $X$ and $Y_{j}$, $j \in\{1, \ldots, N\}$, be Hausdorff topological spaces and $\mathbf{Y}=Y_{1} \times \ldots \times Y_{N}$. For $j \in\{1, \ldots, N\}$, let $J_{j}: X \times Y \rightarrow Z_{j}$ be the payoff functions, where $Z_{j}$ are real normed vector spaces. For all $x \in X$ and for all $j \in\{1, \ldots, N\}$, let $C_{j}(x) \subset Z_{j}$ be a convex, closed and pointed cone, with apex at the origin and with nonempty interior. Let $\leq_{C_{j}(x)}$ denote the partial order induced by $C_{j}(x)$. It means $v-u \in \operatorname{int}\left(C_{j}(x)\right)$ is equivalent to write $u \leq_{\operatorname{int}\left(C_{j}(x)\right)} v$. The norm of $Z_{j}$ is denoted by $\|\cdot\|_{j}$.

The space $X$ will be interpreted as a space of parameters, while $Y_{j}$ as the space of strategies of $j$-th player. Then, $Q_{j}(x) \subset Y_{j}$ is said to be a set of strategies available for player $j$ when parameter $x \in X$ is chosen. The sets $Q_{j}(x)$ are assumed to be nonempty and closed. Furthermore, we denote the strategies sets:

$$
\begin{aligned}
\mathbf{Q}(x) & :=Q_{1}(x) \times \ldots \times Q_{N}(x) \\
\mathbf{Q}_{-j}(x) & :=Q_{1}(x) \times \ldots \times Q_{j-1}(x) \times Q_{j+1}(x) \times \ldots \times Q_{N}(x)
\end{aligned}
$$

and for $y_{j} \in Y_{j}$ let $\mathbf{y}=\left(y_{1}, \ldots, y_{N}\right)$ be identified with $\left(y_{j}, \mathbf{y}_{-j}\right)$, where $\mathbf{y}_{-j} \in \mathbf{Y}_{-j}$ and

$$
\mathbf{Y}_{-j}:=Y_{1} \times \ldots \times Y_{j-1} \times Y_{j+1} \times \ldots \times Y_{N} .
$$

Finally,

$$
\begin{aligned}
\mathbf{J}(x, \cdot) & :=\left(J_{1}(x, \cdot), \ldots, J_{N}(x, \cdot)\right), \\
\mathbf{C}(x) & :=C_{1}(x) \times \ldots \times C_{N}(x),
\end{aligned}
$$

where $J_{j}(x, \cdot)$ denotes the value of the function $J$, if the first variable is chosen as $x$. Therefore, for any $x \in X$, the parametric $N$-player multicriteria game is defined as $\Gamma(x)=(N, \mathbf{Y}, \mathbf{Q}(x), \mathbf{J}(x, \cdot), \mathbf{C}(x))$.

The definition of a parametric weak-multicriteria Nash equilibrium is given after Shapley [18].

Definition 1. $\overline{\mathbf{y}} \in \mathbf{Q}(x)$ is a parametric weak-multicriteria Nash equilibrium if, for all $j=1, \ldots, N$, $\bar{y}_{j}$ is a weak-minimum point of $J_{j}\left(x, \cdot, \overline{\mathbf{y}}_{-j}\right)$ over $Q_{j}(x)$ (i.e., if there does not exist $y_{j} \in Q_{j}(x)$ such that $J_{j}\left(x, y_{j}, \mathbf{y}_{-j}\right) \leq_{i n t C_{j}(x)} J_{j}(x, \overline{\mathbf{y}})$, or in other words, if $\left(J_{j}(x, \overline{\mathbf{y}})-\operatorname{int}\left(C_{j}(x)\right)\right) \cap J_{j}\left(x, Q_{j}(x), \mathbf{y}_{-j}\right)=$ $\varnothing$, for all $j \in\{1, \ldots, N\}$ ).

The set of the parametric weak-multicriteria Nash equilibria of $\Gamma(x)$ will be denoted by $W N(x)$.

Morgan [17] proved the following version of the Berge theorem for a parametricmulticriteria game. The author indicated that the assumptions on payoff functions are minimal, weaker than continuity.

Theorem 1. Let $x \in X$ and $\left(x_{n}\right)_{n}$ be a sequence converging to $x$ in $X$. Assume that the following assumptions are satisfied for all $j=1, \ldots, N$ :

1. For any $\mathbf{y} \in \mathbf{Q}(x)$ and any sequence $\left(\mathbf{y}_{n}\right)_{n} \subset \mathbf{Y}$ such that $\mathbf{y}_{n} \in \mathbf{Q}\left(x_{n}\right)$, for all $n \in \mathbb{N}$, and $\left(\mathbf{y}_{n}\right)$ converges to $\mathbf{y}$, the following condition holds: $d\left(J_{j}(x, \mathbf{y}), J_{j}\left(x_{n}, \mathbf{y}_{n}\right)-C_{j}\left(x_{n}\right)\right) \rightarrow 0$ when $n \rightarrow \infty$;

2. For any $\mathbf{y} \in \mathbf{Q}(x)$ and any sequence $\left(\mathbf{y}_{-j, n}\right)_{n} \subset \mathbf{Y}_{-j}$ converging to $\mathbf{y}_{-j}$ and such that $\mathbf{y}_{-j, n} \in$ $\mathbf{Q}_{-j}\left(x_{n}\right)$, there exists $\bar{y}_{j, n} \in Q_{j}\left(x_{n}\right)$, for all $n \in \mathbb{N}$, such that: $d\left(J_{j}(x, \mathbf{y}), J_{j}\left(x_{n}, \bar{y}_{j, n}, \mathbf{y}_{-j, n}\right)+\right.$ $\left.C_{j}\left(x_{n}\right)\right) \rightarrow 0$ when $n \rightarrow \infty$; 
3. $C_{j}(x) \subset \liminf C_{j}\left(x_{n}\right)$ and there exists $m \in \mathbb{N}$ such that: $\operatorname{int}\left(\bigcap_{m \leq n} C_{j}\left(x_{n}\right)\right) \neq \varnothing$ (which is a redundant assumption if $Z_{j}$ is a finite dimensional space);

4. The set-valued function $Q_{j}$ is sequentially closed at $x$.

Then, the set-valued function $W N$, defined by $W N(x)$ for any $x \in X$, is a sequentially closed set-valued function from $X$ to $\mathbf{Y}$ (i.e., $\left.\lim \sup W N\left(x_{n}\right) \subset W N(x)\right)$ that is to say, if a sequence of parametric weak-multicriteria Nash equilibria corresponding to an approximate value of the parameter $x_{n}$ converges, then it converges to a weak-multicriteria Nash equilibrium corresponding to the limit value $x$ of the sequence $\left(x_{n}\right)_{n}$.

In Theorem 1, the convergence of sequence of sets is understood as the Painleve and Kuratowski convergence (see, e.g., $[17,19])$. To recall, let $\left(A_{n}\right) \subset Z$ be a sequence of subsets. Then,

$\liminf _{n \rightarrow \infty} A_{n}=\left\{x \in Z: \exists\left(x_{n}\right)_{n}\right.$ converging to $x$ such that $x_{n} \in A_{n}$ for $n$ large $\}$

$\limsup _{n \rightarrow \infty} A_{n}=\left\{x \in Z: \exists\left(x_{k}\right)_{k}\right.$ converging to $x$ such that $x_{k} \in A_{n_{k}}$ for a subsequence $\left.\left(n_{k}\right)_{k}\right\}$.

A set-valued function $F: X \rightarrow Y, X, Y$ being a topological space is sequentially closed at $x \in X$ if, for every sequence $\left(x_{n}\right)_{n}$ convergent to $x$, for every sequence $\left(y_{n}\right)_{n}$ convergent to $y$ such that $y_{n} \in F\left(x_{n}\right)$ for all $n \in \mathbb{N}$, one has $y \in F(x)$ (that is, $\limsup _{n \rightarrow \infty} F\left(x_{n}\right) \subset F(x)$ for all $\left(x_{n}\right)_{n}$ convergent to $\left.x\right)$.

\section{Production System of General Equilibrium Model}

The general equilibrium model is usually described in one of two ways: axiomatictopological (compare [1-3]) or game-theoretic (e.g., [18]). In this paper, we are going to focus on the production sector only. Its description will be given in the language of multicriteria games, referring to the general setting provided in the previous section.

We consider the production system consisting of $N$ producers, $j \in\{1, \ldots, N\}$, with $l$ goods available in the market. Then, $P=\mathbb{R}^{l}$ and $Y=\mathbb{R}^{l}$ (identified with $\mathbf{Y}=\left(\mathbb{R}^{l}\right)^{N}$ ) are interpreted as the space of prices and the space of production plans, respectively.

The production abilities and technology available for the $j$-th producer are represented by his production set $Y_{j} \subset Y$. Given the price vector $p \in P$, each producer aims to maximize his profit $\pi_{j}(\cdot)$, i.e.,

$$
\pi_{j}^{*}:=\max \pi_{j}=\max _{y_{j} \in Y_{j}} p \cdot y_{j}
$$

Debreu provided the assumptions, under which the general equilibrium exists. For any producer $j$, his production set $Y_{j}$ satisfies the following conditions (see [1] or [6]):

1. $Y_{j} \subset Y$ is closed (if for any $k$, the production plan $y_{j}^{k} \in Y_{j}$ is possible for $j$-th producer and $\lim _{k \rightarrow \infty} y_{j}^{k}=y_{j}^{0}$, then $y_{j}^{0} \in Y_{j}$, i.e., the limiting plan can also be possible for production);

2. $0 \in Y_{j}$ (the possibility of not producing);

3. $Y_{j} \cap \mathbb{R}_{+}^{l} \subset\{0\}$ (i.e., there is no possibility of free production, without inputs);

4. $Y_{j} \cap\left(-Y_{j}\right) \subset\{0\}$ (irreversibility);

5. $Y_{j}+Y_{j} \subset Y_{j}$ (any two production plans together are also possible to produce);

6. $Y_{j}$ is convex (any combination of two production plans is also possible for production);

7. $Y_{j}$ is a cone with its apex at 0 (under the assumption of constant returns to scale);

8. $\mathbb{R}_{-}^{l} \subset Y$, where $Y=Y_{1}+\ldots+Y_{n}$ (it is possible for all producers together to dispose of all commodities).

Comparing the notation with the previous section, the production sets $Y_{j}$ should be understood as $Q_{j}$, i.e., the sets of available strategies for the $j$-th producer. As all the agents operate in the same space of commodities $\mathbb{R}^{l}$, i.e., $Q_{j} \subset \mathbb{R}^{l}$. 
It is known that maximization of the profit function may be not achievable for any price vector. Therefore, it is necessary to define the correspondence that identifies the price vectors, for which it is possible to find maximum of $\pi_{j}$ :

$$
T_{j}:=\left\{p \in P: \text { there exists } \max _{y_{j} \in Y_{j}} p \cdot y_{j}\right\}
$$

In convex analysis, if $Y_{j}$ is a cone, then the set $T_{j}$ is its normal cone. We define

$$
X:=\bigcap_{j=1}^{N} T_{j}
$$

and assume $X \neq \varnothing$. This assumption assures existence of a price vector that allows to achieve the optimum for all producers simultaneously. Note that the correspondence $\eta_{j}(\cdot) \subset X \times Y_{j}$, assigning the maximal solutions to the price vectors, is nonempty for $p \in X$ :

$$
\eta_{j}(p):=\left\{y_{j}^{*} \in Y_{j}: \pi\left(y_{j}^{*}\right)=\max _{y_{j} \in Y_{j}} p \cdot y_{j}\right\}
$$

\section{Convergence of the Equilibria under Changing Prices}

Theorem 1 can be applied to the production system in the general equilibrium model after some technical modifications.

The natural choice of the Hausdorff spaces $Y_{j}$ would be $\mathbb{R}^{l}$. However, to be precise, we need to redefine the profit functions by a factor of indicator function of the production set, i.e., given $p \in X$ :

$$
\tilde{\pi}_{j}(y):=p \cdot y \cdot \mathbf{1}_{Q_{j}}
$$

Then, the maximization of $\tilde{\pi}_{j}$ over the whole space $Y_{j}=\mathbb{R}^{l}$ is equivalent to the maximization of $\pi_{j}$ over the production set $Q_{j} \subset \mathbb{R}^{l}$. Moreover, with this modification the set $\tilde{T}_{j}=\left\{p \in P\right.$ : there exists max $\left.\tilde{\pi}_{j}\right\}$ can be identified with $\mathbb{R}^{l}$, so trivially, $X=\mathbb{R}^{l}$ is our choice of Hausdorff space of parameters, with no loss of the details of the model, described in the previous section. Obviously, the assumption $\bigcap_{j=1}^{N} T_{j} \neq \varnothing$ is still considered.

The criterion of choosing the best production strategy is the value of maximal profit. Therefore, the natural choice for $Z_{j}$ is $\mathbb{R}$ with standard norm. Finally, the payoff functionals are $J_{j}(p, y)=-\pi_{j}(y)=-p \cdot y$ for $y \in Q_{j}(p)$ and $C_{j}=\mathbb{R}_{+}$for any $j \in\{1, \ldots, N\}$.

\section{Producers' Price War}

The price war between producers can be modelled as a sequence of prices $\left(p_{n}\right)_{n} \subset X$. Assume that it is convergent to some price $p \in X$. Each producer maximizes his profit function $\pi_{j}$ over $Q_{j}\left(p_{n}\right) \subset Y_{j}=\mathbb{R}^{l}$ by choosing optimal $y_{j, n}$ or, equivalently, maximizes $\tilde{\pi}_{j}$ over $Y_{j}=\mathbb{R}^{l}$. Therefore, under conditions made on the production sets, for each $n$, we have a weak-multicriteria Nash equilibrium $\mathbf{y}_{n} \in \mathbf{Q}\left(p_{n}\right) \subset\left(\mathbb{R}^{l}\right)^{N}$. We assume that $\left(\mathbf{y}_{n}\right)$ converges to $\mathbf{y}$ such that $d\left(-\pi_{j}(p, \mathbf{y}),-\pi_{j}\left(p_{n}, \mathbf{y}_{n}\right)-C_{j}\left(p_{n}\right)\right) \rightarrow 0$ when $n \rightarrow \infty$. Moreover, we assume that any production plan $\mathbf{y} \in \mathbf{Q}(\mathbf{p})$ that can be maintained with the final price, can be achieved as a result of optimal production plans in this price war. More precisely, we assume that any production plan $\mathbf{y} \in \mathbf{Q}(\mathbf{p})$ and any sequence of production plans for all but $j$-th producers $\left(\mathbf{y}_{-j, n}\right)_{n} \subset \mathbf{Y}_{-j}$ converging to $\mathbf{y}_{-j}$ and being optimal in $n$-th step: $\mathbf{y}_{-j, n} \in \mathbf{Q}_{-j}\left(p_{n}\right)$, the $j$-th producer optimizes his profit function by choosing $\bar{y}_{j, n} \in Q_{j}\left(x_{n}\right)$, which approximates his final optimal production plan $\mathbf{y}_{j}$, i.e., $d\left(J_{j}(x, \mathbf{y}), J_{j}\left(x_{n}, \bar{y}_{j, n}, \mathbf{y}_{-j, n}\right)+C_{j}\left(x_{n}\right)\right) \rightarrow 0$ when $n \rightarrow \infty$. Under those assumptions, we can state that given any price war scenario $\left(p_{n}\right)$ that converges to a price vector $p$, if only the actions of producers (chosen as the parametric weak-multicriteria Nash equilibria in reaction to the prices $\left(p_{n}\right)$ ) converge, then their limit is optimal for the limit price $p$. In other words, acting optimally in the price war, the producers end up in the optimal state at the end of this war. 
The question that remains open is the influence of the price war between the producers on the consumption system. The research indicates that, initially, they take the advantage of the lower prices which allow a choice in a wider consumption set. However, to the best of our knowledge, it was not modelled in the context of the general equilibrium.

Funding: This research was supported by Narodowe Centrum Nauki, grant no. 2018/02/X/HS4/00893.

Institutional Review Board Statement: Not applicable.

Informed Consent Statement: Not applicable.

Acknowledgments: The author would like to thank the anonymous reviewers whose valuable and constructive comments helped improve and clarify the manuscript.

Conflicts of Interest: The author declares no conflict of interest.

\section{References}

1. Debreu, G. Theory of Value; Yale University Press: London, UK, 1959.

2. Ciałowicz, B.; Malawski, A. Demand-driven Schumpeterian innovative evolution-An axiomatic set-up. In Catching Up, Spillovers and Innovations Networks in a Schumpeterian Perspective; Pyka, A., Derengowski, F., da Graca, M., Eds.; Springer: Berlin/Heidelberg, Germany, 2011

3. Lipieta, A.; Malawski, A. Price versus Quality Competition: In Search of Schumpeterian Evolution Mechanisms. J. Evol. Econ. 2016, 26, 1137-1171.;1-35. [CrossRef]

4. Schumpeter, J.A. Die Theorie der Wirtschaftlichen Entwicklung; Duncker\&Humbol: Leipzig, Germany, 1912; English translation: The Theory of Economic Development; Harvard University Press: Cambridge, MA, USA, 1934.

5. Malawski, A. Innovative Economy as the Object of Investigation in Theoretical Economics, 1st ed.; Wydawnictwo Uniwersytetu Ekonomicznego w Krakowie: Kraków, Poland, 2013.

6. Kornafel, M.; Denkowska, A. Producer optima in Schumpeterian evolution. Zeszyty Naukowe Uniwersytetu Ekonomicznego w Krakowie 2017, 10, 55-66. [CrossRef]

7. Assael, H. Marketing; Prentice Hall: Englewood Cliffs, NJ, USA, 1990.

8. Urban, G.L.; Star, S.H. Advanced Marketing Strategy: Phenomena, Analysis, and Decisions; Prentice Hall: Englewood Cliffs, NJ, USA, 1991.

9. Busse, M. Firm financial condition and airline price wars. RAND J. Econ. 2002, 33, 298-318. [CrossRef]

10. Heil, O.P.; Helsen, K. Toward an understanding of price wars: Their nature and how they erupt. Int. J. Res. Mark. 2001, 18, 83-98. [CrossRef]

11. Wenliang, M.; Qiang, W.; Hangjun Y.; Yahua, Z. An analysis of price competition and price wars in Australia's domestic airline market. Transp. Policy 2019, 81, 163-172

12. Xiangbin, X.; Ermin, Z. Research on Price Wars in Supply Chain Networks Based on Multistage Evolutionary Prisoner's Dilemma Game. Hindawi Math. Probl. Eng. 2019, 2019, 5106792. [CrossRef]

13. Agbaeze, E.; Ngozichukwu, C.M.; Ogbo, A.; Ukpere, W.I. Impact of Pricing Practice Management on Performance and Sustainability of Supermarkets in the Urban Area of Enugu State, Nigeria. Sustainability 2020, 12, 6019. [CrossRef]

14. Moorthy, K.S. Using Game Theory to Model Competition. J. Mark. Res. 1985, 22, 262-282. [CrossRef]

15. Saloner, G. Modeling, Game Theory, and Strategic Management. Strateg. Manag. J. 1991, 12, 119-136. [CrossRef]

16. Ba, S.; Stallaert, J.; Zhang, Z. Online Price Dispersion: A Game-Theoretic Perspective and Empirical Evidence. Inf. Syst. Res. 2012, 23, 575-592. [CrossRef]

17. Morgan, J. Approximations and Well-Posedness in Multicriteria Games. Ann. Oper. Res. 2005, 137, 257-268. [CrossRef]

18. Shapley, L.S. Equilibrium Points in Games with Vector Payoffs. Nav. Res. Logist. Q. 1959, 6, 57-61. [CrossRef]

19. Kuratowski, K. Topologie I et II, 2nd ed.; PWN, Monografie Matematyczne: Warszawa, Poland, 1961. 